We also be partnered with TransforMed to offer a 4-hour preconference session at the conference, Conference on Practice Improvement Learning Collaborative: A Partnership with TransforMED. This session provided a face-to-face networking opportunity for practices that wanted to learn more about the TransforMED PCMH model. This program will also provide ongoing communication between participants and will provide the opportunity for coaching from TransforMED facilitators. Participants were exposed to the collaborative learning style which, when combined with the experience, tools, and expertise of the TransforMED facilitators, provided the foundation for maintaining the success of the TransforMED NDP. This new program offered a jump-start on the TransforMED process and provided resources for making the needed changes within a practice.

Those attending this session learned to:

1. Identify the elements of a PCMH

2. Articulate the importance of the foundational components of leadership, teamwork, and communication to the development, ongoing implementation, and successful transition to the medical home practice

3. Communicate a basic understanding of the requirements for practice recognition as a $\mathrm{PCMH}$

4. Create an understanding of the integrated care management process

5. Formulate a plan for assessing the practice's current stage of medical home readiness and develop a plan for further implementation of the elements of the model

A follow-up program will be offered at the 2009 STFM Annual Meeting in Denver.

6) Competency Curriculum Modules: Four competencybased curriculum modules related to the PCMH are posted on STFM's Family Medicine Digital Resources Library (http://www.fmdrl.org), and we're beginning to share information on these materials in our publications. ADFM has shared these links on its listserve, along with favorable reviews of the materials. Our Group on Evidence-based Medicine is working on a new module.

- Competency-based Curriculum: Group Visits

- Competency-based Curriculum: Chronic Care Model

- Competency-based Curriculum: Quality Improvement

- Competency-based Curriculum: Advance Access 7) Otber PCMH Activities:

- The PCMH has been or will be the conference theme for our major conferences, including the 2009 annual meeting with the theme, "Transforming Education to Meet the Needs of the Personal Medical Home." We'll feature a PCMH track as part of the 2009 annual meeting offerings.
- We have published several articles in Family Medicine (including 7 president's columns by John Rogers, which are available as a set on FMDRL) and the STFM Messenger.

- In addition to the competency curriculum modules, there are other documents on FMDRL that relate to the $\mathrm{PCMH}$.

- The STFM Education Committee is putting together a matrix of resources to assist members' practices in becoming PCMHs.

- STFM participates in the Council of Academic Family Medicine, which has a subcommittee focused on the PCMH. This subcommittee is looking at opportunities to incorporate mental health into the PCMH. They are also looking at ways to collect information on $\mathrm{PCMH}$ adoption in residency education.

Jobn Rogers, MD, MPH, Med

Caryl Heaton, DO

Chairs, STFM Group on the Patient-centered Medical Home

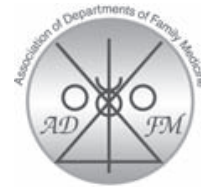

From the Association

of Departments of Family Medicine

Ann Fam Med 2009;7:90-91. DOI: 10.1370/afm.953.

\section{ADVANCED ACCESS IN ACADEMIC SETTINGS: DEFINITIONAL CHALLENGES}

Enhanced access to care is a hallmark of the patientcentered medical home. The first standard in National Committee for Quality Assurance (NCQA) criteria for certification as a medical home requires that practices have written standards for patient access and communication, and that they use data to show they meet these standards. Methods by which practices may do so include open scheduling, expanded hours, and new options for communication between patients, their personal physician, and practice staff.

One solution for reducing delays for appointments is advanced access scheduling — strictly defined as offering each patient an appointment with their preferred clinician at the time of their choice-which is touted as a way for ambulatory practices to improve both access and continuity. Many community practices have experienced success with this scheduling model by demonstrating increased appointment availability, increased patient satisfaction, decreased no-show rates, and increased revenues.

Within academic practices, delayed access is exacerbated by faculty and residents who are only part-time within their continuity practices, day-to-day variation 
in provider availability, and communication difficulties when residents are on hospital-based rotations which limit their ambulatory clinical time. The same factors contribute to significant challenges in maintaining patient-provider continuity. Outcomes reported within the few published studies on advanced access scheduling in academic settings have shown varying results. ${ }^{1-4}$

Despite widespread agreement regarding the importance of advanced access, there is a broad diversity of understanding of just what the terms "advanced" or "open" access mean. A 2007 survey of Chairs of Departments of family medicine reveals progress toward the goal of improving access, yet reveals some of the challenges. Over one-half of respondents indicated that they had implemented advanced access scheduling, with two-thirds indicating that they measure and report access data internally or to their health system partners. Yet, fewer than one-half regularly measure the impact of access on continuity or no-show rates. While $49 \%$ felt that their no-show rate improved modestly or significantly, $16 \%$ reported only marginal improvement and more than one-third no improvement or worsening of no-show rates. Only 29\% felt that individual continuity rates had improved, while the remainder felt that rates were either unchanged or had declined.

One explanation of these varied findings relate to definitional confusion among practices reporting access outcomes. In this same survey, respondents were asked to describe the model of access that they utilize. Descriptions of access models varied considerably. Nearly one-third described their access model as: "triage physician of the day," "work-ins," "walk-in care," and "filling no-show slots." The remaining two-thirds described a carve-out model of access, with significant variation in the degree of carve-out involved, ranging anywhere from $10 \%$ to $80 \%$ of appointments. The appointment "thaw" time also varied considerably, from 14 days to 24 hours prior to appointment time.

The goal of a patient-centered model of appointment access is to give each patient an appointment with their preferred clinician when the patient wants and/or needs to be seen. Yet, access management in academic settings is challenged by interrupted continuity clinic schedules and day-to-day variation in provider availability. Despite this, nearly two-thirds of responding academic departments of family medicine have made the effort toward building this portion of the medical home. Current efforts have been subject to common pitfalls, include managing appointment demand with little attention to continuity of individual or team care; attempting to improve access without truly balancing supply and demand; allowing too much appointment backlog to remain, and limiting patients ability to book future appointments into the future.
The tools for creating access into the medical home (matching appointment supply and demand to eliminate delays; reducing appointment types to maximize appointment supply; reducing appointment demand; working down the backlog to eliminate delays; and planning for contingencies to prevent future delays from reforming) are clearly defined and doable, even in complex academic settings. In order to achieve a model of integrated, comprehensive care from the patient's perspective, academic practices must move beyond defining access as having a triage doctor of the day, or working patients in to an already packed schedule. Rather, we must persist in working toward true models of access management. It is only then that we will be able to provide patient-centered care, educate medical students and residents in redesigned practices of the future, and compare our outcomes based on congruent methods of definition and implementation.

Elizabeth G. Baxley, MD

University of South Carolina School of Medicine, Columbia, SC

Sam Weir, MD

University of Nortb Carolina School of Medicine, Chapel Hill, NC and the Association of Departments of Family Medicine

\section{References}

1. Kennedy JG, Hsu JT. Implementation of an open access scheduling system in a residency training program. Fam Med. 2003;35(9):666-670.

2. Belardi FG, Weir S, Craig FW. A controlled trial of an advanced access appointment system in a residency family medicine center. Fam Med. 2004;36(5):341-345.

3. Steinbauer JR, Korell K, Erdin J, Spann SJ. Implementing openaccess scheduling in an academic practice. Fam Prac Manage. 2006:13(3):59-64

4. Bennett KJ, Baxley EG. The effect of a carve-out advanced access scheduling system on no show rates. Fam Med. 2009;41(1).

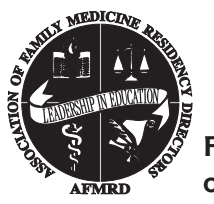

From the Association of Family Medicine Residency Directors

Ann Fam Med 2009;7:91-92. DOI: 10.1370/afm.954.

\section{FAMILY MEDICINE RESIDENT AWARD FOR SCHOLARSHIP}

The need for capacity building in family medicine research is well recognized. One strategy for accomplishing this goal is to mentor and recognize residents for their accomplishments in scholarly activities. The Association of Family Medicine Residency Directors (AFMRD), the North American Primary Care Research Group (NAPCRG), and the College of Family Physicians of Canada (CFPC) have developed the 